\title{
A Clinical Study of Cutaneous Manifestations in Patients on Cancer Therapy at a Tertiary Care Hospital
}

\author{
Krishnakanth Muralidhar'1, Roopa Raghupathy², Sudha Rangarajan³ , Mahalakshmi Veeraraghavan", \\ Murugan Sundaram ${ }^{5}$ \\ ${ }^{1}$ Department of Dermatology, Sri Ramachandra Institute of Higher Education and Research, Chennai, \\ Tamilnadu, India. ${ }^{2}$ Department of Dermatology, Sri Ramachandra Institute of Higher Education and \\ Research, Chennai, Tamilnadu, India. ${ }^{3}$ Department of Dermatology, Sri Ramachandra Institute of Higher \\ Education and Research, Chennai, Tamilnadu, India. ${ }^{4}$ Department of Dermatology, Sri Ramachandra \\ Institute of Higher Education and Research, Chennai, Tamilnadu, India. ${ }^{5}$ Department of Dermatology, Sri \\ Ramachandra Institute of Higher Education and Research, Chennai, Tamilnadu, India.
}

\section{ABSTRACT}

\section{BACKGROUND}

The aim of cancer treatment is to target and destroy cancer cells. Adversely it affects rapidly dividing cells of bone marrow, hair, nails, skin and gastrointestinal mucosa. Drug induced side effects are seen in $25 \%$ of hospitalized cancer patients resulting in a variety of cutaneous adverse effects. This study analyses the cutaneous manifestations in patients on cancer therapy at a tertiary care hospital.

\section{METHODS}

This is a hospital based observational study, done over a period of 2 years (September 2016 - September 2018), on cancer patients undergoing chemo or radiotherapy having cutaneous manifestations, referred to the Dermatology OPD from Oncology OPD in a tertiary hospital.

\section{RESULTS}

Among 106 cases, 47\% were males and 53\% were females. Majority of patients belonged to the age group of 41-60 years (40\%). Carcinoma of breast $(13 \%)$ and lung $(9 \%)$ presented in highest frequency. Out of 59 patients who were treated with chemotherapy alone, most common was anagen effluvium (59\%) and least common were ichthyosis, erythema multiforme and herpes zoster (each 2\%). Among 5 patients who were treated with radiation therapy alone, most common was radiation dermatitis and seborrheic dermatitis (each $40 \%$ ). Among 18 patients who underwent combined chemo and radiotherapy, most common was anagen effluvium (39\%) and least was folliculitis, lichenoid dermatitis (each 7\%). Among 8 patients who underwent surgery followed by adjuvant chemotherapy, most common was anagen effluvium (40\%) and least was surgical site infection, eczema, folliculitis (each 12\%). Among 16 patients who underwent combined chemo, radiation and surgery, most common was anagen effluvium (25\%) and least common was surgical site infection (6\%). 14\% fungal, 10\% bacterial and 6\% viral infections were noted. Among 101 patients who received at least 1 chemotherapeutic agent, most commonly used agent was cisplatin $(50 \%)$ and least commonly used agent was gemcitabine (3\%).

\section{CONCLUSIONS}

Early identification of adverse effects might help us to give a better quality of life and reduce psychosomatic distress of the patients. It might also assist in tailoring the therapy accordingly.

\section{KEY WORDS}

Cutaneous Manifestations, Cancer, Chemotherapy, Radiotherapy, Surgery, Infections
Corresponding Author: Dr. Krishnakanth Muralidhar, Flat No. 1132, TVH Lumbini Squar Flats, \#127A, Brick Lin Road, Purashawalkam, Chennai-600007, Tamilnadu, India. E-mail: krishnakanthmuralidhar@gmail.com

DOI: $10.14260 /$ jemds/2020/21

Financial or Other Competing Interests: None.

How to Cite This Article: Muralidhar K, Raghupathy R, Rangarajan $S$, et al. A clinical study of cutaneous manifestations in patients on cancer therapy at a tertiary care hospital. J. Evolution Med. Dent. Sci. 2020;9(02):97100, DOI: $10.14260 / \mathrm{jemds} / 2020 / 21$

Submission 13-11-2019,

Peer Review 28-12-2019,

Acceptance 03-01-2020,

Published 13-01-2020. 


\section{BACKGROUND}

Cancer is one of the most important causes of death and morbidity in both developed and developing parts of the world. Worldwide, around 14.1 million individuals are diagnosed with cancer annually. Out of 8.2 million cancer mortalities, 58\% occurred in less developed regions.[1] Cancer burden is estimated to grow exponentially in the future. There are over 200 kinds of cancer and there are still many facts unknown about the disease.[2,3] The aim of cancer treatment is to destroy the cancer cells. Cancer cure today revolves around chemotherapy. Toxic anticancer drugs with low therapeutic index are prescribed to more than $50 \%$ cancer patients although their overall cure is only about $2 \%$ $5 \%$. Cutaneous manifestations are considered an indispensable component of cancer therapy. Hence, they are stoically accepted by patients and health care providers.

Cutaneous side effects due to radiotherapy are common and sometimes are severe which might lead to reduction in the treatment duration. The effects may be acute or chronic. Acute effects occur hours to weeks after exposure to radiation and are characterized by erythema, oedema, hyperpigmentation, scaling and alopecia. Chronic effects are more severe and occur months to years after the exposure and present as ulcers, necrosis and fibrosis. Chemotherapy is related to multiple dermatological changes such as alopecia, erythema, acne, hypersensitivity reactions, itch, xerosis, local desquamation and nail changes. The lack of a truly curative, safe drug, and the elevating burden of cancer necessitates rapid anticancer drug improvement and accelerated approval. In recent years, a tremendous breakthrough has been made towards the knowledge of cancer specialty and its management. Many new targeted drugs are being developed continuously. However, with its increasing prevalence, cancer management progresses to be a challenge for the current era of clinical medicine.

We wanted to evaluate the cutaneous manifestations of patients on cancer therapy at a tertiary care hospital. We also wanted to document the demographics, clinical history, and investigations.

\section{METHODS}

This hospital based observational study was done for a period of 2 years after obtaining the ethical clearance from ethics department (September 2016-September 2018). It was conducted on patients with any form cancer who developed cutaneous changes that have developed only after or during the course of cancer therapy, referred from Oncology OPD to Dermatology OPD in a tertiary care hospital. The patients underwent detailed history taking and clinical examination. Patients who developed cutaneous manifestations during the course of treatment as a result of internal malignancies were documented. Patients who had muco-cutaneous symptoms prior to the initiation of therapy and patients who did not give consent were excluded.
RESULTS

Among the 106 cases in the study (sample size was calculated according to the average patients recorded in oncology department for a period of 2 years), there were 50 male patients (47\%) and 56 female patients (53\%). Majority of patients affected belonged to the age group between 41- 60 $(40 \%)$ years contributing to with a mean age of $48 \pm 5$ years. Majority of the patients presented with primary carcinoma of breast $(13 \%)$ and lung (9\%) followed by carcinoma ovary (8\%), carcinoma stomach (7\%), Non-Hodgkin's lymphoma, CML and ALL (6\%), Hodgkin's lymphoma, AML and carcinoma urinary bladder (5\%), carcinoma rectum, oesophagus, cervix and carcinoma tongue (4\%), Carcinoma endometrium and colon (3\%). Among 106 cases, 59 cases underwent chemotherapy, 5 cases were treated with radiation alone, 18 cases were treated with chemo and radiation, 8 cases underwent chemo and surgery and remaining 16 cases were treated with all the three therapies. Among 106 cases, 64 cases were treated with single therapy and remaining cases were treated with combined therapy.

\section{Chemotherapy Only}

Out of 59 chemotherapy cases majority of cutaneous adverse effects observed was anagen effluvium (59\%) followed by xerosis (7\%), hyper pigmentation (7\%), melanonychia (5\%), prurigo nodularis (5\%) and Eczema (4\%) as mentioned in Table 3.1.

\begin{tabular}{|c|c|c|}
\hline Cutaneous Adverse Reaction & No. of Cases (n=59) & Percentage (\%) \\
\hline Anagen effluvium & 33 & 59 \\
\hline Xerosis & 4 & 7 \\
\hline Supravenous hyperpigmentation & 4 & 7 \\
\hline Melanonychia & 3 & 5 \\
\hline Prurigo nodularis & 3 & 5 \\
\hline Eczema & 3 & 4 \\
\hline Nail dystrophies & 3 & 4 \\
\hline Folliculitis & 3 & 4 \\
\hline Herpes zoster & 1 & 2 \\
\hline Erythema multiforme & 1 & 2 \\
\hline Ichthyosis & 1 & 1 \\
\hline \multicolumn{2}{|c|}{ Total } & $\mathbf{5 9}$ \\
\hline Table 1. Cutaneous Adverse Effects of Chemotherapy
\end{tabular}

\section{Chemotherapy and Radiotherapy}

Among 18 patients, anagen effluvium was observed in majority $(39 \%)$ of patients followed by oral candidiasis (16\%), radiation dermatitis (16\%), eczema (16\%), folliculitis (7\%). Among these 18 cases we also observed a case of lichenoid dermatitis in 1 patient (7\%).

\section{Surgery with Adjuvant Chemotherapy}

Among 8 patients, majority of the patients were affected by anagen effluvium (40\%) followed by xerosis (24\%).

\section{Combined Chemotherapy, Radiation and Surgery}

Out of 16 patients, anagen effluvium was observed in 4 patients (25\%), xerosis, radiation dermatitis and folliculitis were observed in each three (19\%) patients.

\section{Chemotherapeutic Agents}

As enlisted in Table 3.2, among chemotherapeutic agents 
used in 101 patients, maximum number of patients received cisplatin 53 (50\%), followed by cyclophosphamide in 24 patients (23\%), methotrexate in 24 patients (23\%), carboplatin in 21 patients (20\%), paclitaxel in 20 patients (19\%), 5-fluorouracil in 18 patients (17\%).

\begin{tabular}{|c|c|c|}
\hline Chemotherapeutic Agents Used & No. of Patients & Percentage (\%) \\
\hline 5 - fluorouracil & 18 & 17 \\
\hline Vincristine & 6 & 6 \\
\hline Carboplatin & 21 & 20 \\
\hline Cyclophosphamide & 24 & 23 \\
\hline Cisplatin & 53 & 50 \\
\hline Doxorubicin & 17 & 16 \\
\hline Methotrexate & 24 & 23 \\
\hline Oxaliplatin & 6 & 6 \\
\hline Daunorubicin & 9 & 9 \\
\hline Docetaxel & 6 & 6 \\
\hline Paclitaxel & 20 & 19 \\
\hline Epirubicin & 8 & 8 \\
\hline Capecitabine & 4 & 4 \\
\hline ABVD regimen & 5 & 5 \\
\hline Gemcitabine & 3 & 3 \\
\hline Table 2. Chemotherapeutic Agents Responsible for Cutaneous \\
\hline \multicolumn{2}{|c|}{ Manifestations } \\
\hline
\end{tabular}

Among 101 patients who underwent chemotherapy treatment, 22 patients were treated with single chemotherapy agents, 37 were treated with two drugs, 26 were treated with three drugs and 16 patients were treated with more than three chemotherapy agents.

\section{Infections}

Among 106 patients, fungal infection was observed in 12 cases $(14 \%)$ in which the most common was oral candidiasis followed by bacterial infection 8 cases $(10 \%)$ in which the most common was folliculitis and viral infection 5 cases(6\%) in which the most common was Herpes zoster.

\section{Nail Changes}

Among 106 patients the most common finding was Melanonychia seen in 5 cases (5\%) followed by Nail dystrophies in 4 cases (4\%).

\section{DISCUSSION}

In the present study, female patients on cancer therapy presented with cutaneous manifestations more than men which is similar to a study on cancer subjects in Madhya Pradesh and Uttar Pradesh of India by Ganjewala D et al,[4] where occurrence of all type of cancers in both states were significantly high in women. This is particularly because of more numbers of cervical and breast carcinoma subjects. In our study most of the patients who suffered belonged to the age group between 41 to 60 (40\%) years followed by $0-20$. contributing with average age of $48 \pm 5$ years. Our finding is similar to the study carried out by Sharma et al[5] that showed adverse effects in the 41- 60 years age group. This finding is also similar to the report of Pai et al[6] who also reported average age of subjects 55.98 years and 52.96 years in men and women respectively and likewise, a study of Behera et al[7] which showed adverse reactions in 41-60 years age group was highest. This can be because of the high occurrence of cancers in this particular age group.

In this study number of carcinoma breast and lung were comparatively more irrespective of sex followed by ovary, stomach, Non-Hodgkin's lymphoma, CML, ALL, Hodgkin's lymphoma, AML, urinary bladder, rectum, oesophagus, cervix, tongue, endometrium and colon. The most frequently occurring cancers in men was lung and in women carcinoma breast and ovary. Researches carried out in India (Nandakumar A. et al \& Ganjewala D. et al) and[8],[4] and Pakistan (Khan SM et al) [162] have shown variation in prevalence of different cancers. The generally identified type of hair loss due to chemotherapy is anagen effluvium. Preponderance $(79.4 \%)$ of the suffered subjects identified considerable hair loss within 3 to 6 weeks of beginning of treatment. It was in accordance with the studies by Yun \& Kim et al.[9] In our study Xerosis was seen in $11 \%$ patients followed by eczema (8\%). Majority of them (53.9\%) noticed skin lesions by 4 to 6 th week of therapy. Abnormal keratinocyte differentiation which leads to an impaired sebaceous gland function and loss of ability to retain water may be the cause of xerosis. A similar study by Pavey et al[10] found incidence of xerosis was $(22.2 \%)$ but the commencement of lesion was identified initially at 2 to 4 weeks.

Another study by Fabbrocini et al[11] suggested an occurrence of $41.7 \%$ of xerosis in his study. The drug found to cause xerosis in this study are cyclophosphamide, carboplatin, cisplatin and vincristine. In this study among 18 patients who received chemo and radio therapy, we found a presentation of lichenoid dermatitis in one subject who received capecitabine. Lichenoid skin reaction is uncommon skin characteristic of cancer chemotherapy. A study by Rena SA et al [12] observed and reported capecitabine induced lichenoid skin reaction in their case report study. In the earlier study capecitabine induced lichenoid skin reaction was also reported in the dermatological literature by Hague JS et al [13] and Walker G et al[14] which is also similar to our findings. In our present study we observed radiation dermatitis in $8(28 \%)$ cases among 29 patients who received radiation therapy. A study of Jingxian Ding et al[15] reported $19.1 \%$ of radiation induced dermatitis.

Radiation induced dermatitis may affect patient's compliance with the treatment and may be a crucial reason reason for discontinuing the administration of a potentially curative treatment. In the present study an important finding of supra venous hyperpigmentation was found in 4 (7\%) patients who received chemotherapy. Pavey et al and Chiewchanvit et al observed a frequency of $22.2 \%$ and $31.3 \%$ of hyper pigmentation in their particular studies. The chemotherapeutic agent found to produce hyperpigmentation in current study were cyclophosphamide, Fluorouracil (5 FU). Of these drugs, Fluorouracil (5 FU) and cyclophosphamide have been reported in the study of Pujol RM et al[16] and Schulte Huermann $P$ et al[17] to produce hyperpigmentation. Nail alterations is generally shown after several weeks after Commencement of treatment probably because of the slow growth rate of the nail plate. Pavey et al. observed that nail alterations (62.2\%) were the more frequent cutaneous side effect and it was considerably more when compared to current study. In the present study, melanonychia $(5 \%)$ was the more common, after the nail dystrophies (4\%). Chiewchanvit et al. in his study observed melanonychia in $18.9 \%$ of patients. Medicines found to be responsible for melanonychia in current study was epirubicin and cisplatin. 
Kim et al. reported nail hyperpigmentation secondary to management with drug cisplatin. In current study, the more frequent offending platinum analogue was cisplatin 53\% after carboplatin $20 \%$ and least with oxaliplatin (6\%) among chemotherapy treated patients. It is most similar to the study carried out by Swathi et al[18] that showed the suspected drug was cisplatin (64.58\%) after carboplatin (25\%) and oxaliplatin $(10.41 \%)$; this might be because of more frequent use of cisplatin-based chemotherapy. Among infections reported in current study, bacterial, fungal and viral infections constituted $10 \%, 14 \%$ and $6 \%$ respectively. Chiewchanvit et al ${ }^{[19]}$ stated an occurrence of $8.1 \%$ for fungal infections and $4 \%$ for viral infections. This may be attributed to myelosuppression and alteration in immune system function in patients undergoing chemotherapy.

\section{CONCLUSIONS}

The most common cutaneous manifestation noted was Anagen effluvium $>$ Xerosis. The most common agent found responsible was Cisplatin. The least common agent found responsible was Gemcitabine. Educating patients about the adverse effects results in better acceptance and compliance of the patient.

\section{REFERENCES}

[1] World Health Organisation. Latest World Cancer Statistics Global Cancer Burden Rises to 14.1 Million New Cases in 2012; In: WHO International Agency for Research on Cancer ed. Lyon, France and Geneva, Switzerland, 2013.

[2] Miller KD, Siegel RL, Lin CC, et al. Cancer treatment and survivorship statistics, 2016. CA Cancer J Clin 2016;66(4):271-89.

[3] Parveen R, Rahman SS, Sultana SA, et al. Cancer types and treatment modalities in patients attending at delta medical college hospital. Delta Medical College Journal 2015;3(2):1-6.

[4] Ganjewala D. Prevalence of cancers in some parts of Madhya Pradesh and Uttar Pradesh in India. Acad J Cancer Res 2009;2(1):12-8.

[5] Sharma A, Kumari KM, Manohar HD, et al. Pattern of adverse drug reactions due to cancer chemotherapy in a tertiary care hospital in South India. Perspectives in Clinical Research 2015;6(2):109-15.
[6] Bellare PS, Ashwin K, PU SP, et al. A retrospective evaluation of adverse drug reactions due to cancer chemotherapy in a tertiary care hospital in South India. J Young Pharm 2016;8(3):251-4.

[7] Behera SK, Kishtapati CR, Gunaseelan V, et al. Chemotherapy induced adverse drug reactions in cancer patients in a tertiary care hospital in South India. J Young Pharm 2015;6(2):109-15.

[8] Nandakumar A, Ramnath T, Chaturvedi M. The magnitude of cancer cervix in India. Indian J Med Res 2009;130(3):219-21.

[9] Lee MW, Seo CW, Kim SW, et al. Cutaneous side effects in non-small cell lung cancer patients treated with Iressa (ZD1839), an inhibitor of epidermal growth factor. Acta Derm Venereol 2004;84(1):23-6.

[10] Pavey RA, Kambil SM, Bhat RM. Dermatological adverse reactions to cancer chemotherapy. Indian J Dermatol Venereol Leprol 2015;81(4):434.

[11] Fabbrocini G, Cameli N, Romano MC, et al. Chemotherapy and skin reactions. J Exp Clin Cancer Res 2012;31:50.

[12] Shah RA, Bennett DD, Burkard ME. Photosensitive 1 lichenoid skin reaction to capecitabine. BMC Cancer 2017;17(1):866.

[13] Hague JS, Ilchyshyn A. Lichenoid photosensitive eruption due to capecitabine chemotherapy for metasta tic breast cancer. Clin Exp Dermatol 2007;32(1):102-3.

[14] Walker G, Lane N, Parekh P. Photosensitive lichenoid drug eruption to capecitabine. J Am Acad Dermatol 2014;71(2):e52-3.

[15] Ding J, Guo Y, Li Q, et al. The incidence of postoperative radiotherapy-induced acute dermatitis in breast cancer $\&$ its influencing factors for Chinese women. Onco Targets Ther 2018;11:1665-70.

[16] Pujol RM, Rocamora V, Lopez-Pousa A, et al. Persistent supravenous erythematous eruption: a rare local complication of intravenous 5 fluorouracil therapy. J Am Acad Dermatol 1998;39(5 Pt 2):839-42.

[17] Schulte-Huermann $\quad P, \quad$ Zumdick $M$, Ruzicka T. Supravenous hyperpigmentation in association with CHOP chemotherapy of a CD30 positive anaplastic largecell lymphoma. Dermatology 1995;191(1):65-7.

[18] Swathi B, Bhavika D, Begum N. Adverse drug reaction profiles of commonly used Platinum compounds in cancer chemotherapy. Int J Basic Clin Pharmacol 2015;4(2):284-9.

[19] Chiewchanvit S, Noppakun K, Kanchanarattanakorn K. Mucocutaneous complications of chemotherapy in 74 patients from Maharaj Nakorn Chiang Mai Hospital. J Med Assoc Thai 2004;87(5):508-14. 